\title{
Review Article \\ Recent Progress in Synthesis and Application of Low-Dimensional Silicon Based Anode Material for Lithium Ion Battery
}

\author{
Yuandong Sun, Kewei Liu, and Yu Zhu \\ Department of Polymer Science, University of Akron, 170 University Ave, Akron, OH 44325, USA \\ Correspondence should be addressed to Yu Zhu; yu.zhu@uakron.edu
}

Received 10 February 2017; Accepted 28 March 2017; Published 31 July 2017

Academic Editor: Jianlin Li

Copyright (C) 2017 Yuandong Sun et al. This is an open access article distributed under the Creative Commons Attribution License, which permits unrestricted use, distribution, and reproduction in any medium, provided the original work is properly cited.

\begin{abstract}
Silicon is regarded as the next generation anode material for LIBs with its ultra-high theoretical capacity and abundance. Nevertheless, the severe capacity degradation resulting from the huge volume change and accumulative solid-electrolyte interphase (SEI) formation hinders the silicon based anode material for further practical applications. Hence, a variety of methods have been applied to enhance electrochemical performances in terms of the electrochemical stability and rate performance of the silicon anodes such as designing nanostructured $\mathrm{Si}$, combining with carbonaceous material, exploring multifunctional polymer binders, and developing artificial SEI layers. Silicon anodes with low-dimensional structures (0D, 1D, and 2D), compared with bulky silicon anodes, are strongly believed to have several advanced characteristics including larger surface area, fast electron transfer, and shortened lithium diffusion pathway as well as better accommodation with volume changes, which leads to improved electrochemical behaviors. In this review, recent progress of silicon anode synthesis methodologies generating low-dimensional structures for lithium ion batteries (LIBs) applications is listed and discussed.
\end{abstract}

\section{Introduction}

Since the invention of first commercial lithium ion battery in 1990s, LIBs have become the most popular and dominant energy storage device powering light electronics, owing to its high energy density, high operating voltage, low selfdischarge, and slight memory effect [1-4]. Current commercial lithium ion batteries are manufactured based on the graphite anodes and lithium cobalt oxide cathodes [5]. The mechanism for graphite anode material is based on the intercalation of lithium into the layers of graphite bulk crystal by forming $\mathrm{Li}_{x} \mathrm{C}_{6}$ alloy [6], endowing a stable and safe electrochemical behavior for graphite anodes. However, the relatively low theoretical capacity $(372 \mathrm{mAh} / \mathrm{g})$ and poor ratability of graphite failed to meet the growing social and industrial demand, holding it back for further critical applications as electric vehicles and grid-scale energy storage systems [7-9].

Tremendous work has been done focusing on developing a promising anode material with higher capacity and reasonable cycle life. Dey et al. and Boukamp et al. found that lithium could alloy with many electrochemically active materials under room temperature including $\mathrm{Sn}, \mathrm{Pb}, \mathrm{Al}, \mathrm{Au}$, $\mathrm{Pt}, \mathrm{Zn}, \mathrm{Cd}$, and Si $[10,11]$, among which silicon has shown great potential to be the next generation anode material for LIBs with its theoretical capacity of $4200 \mathrm{mAh} / \mathrm{g}$ and high abundance on earth (Figure 1) [11].

The alloying process of lithium and silicon could generate various formations of Li-Si alloys as shown in Table 1. Each silicon atom could accommodate with 4.4 lithium atoms [12, 13], forming $\mathrm{Li}_{22} \mathrm{Si}_{5}$ alloy, leading to the highest theoretical capacity among the electrochemically active materials [14]. However, severe problems are still confronted before using Si anode for practical applications [15, 16]: silicon undergoes huge volume expansion and shrinkage in lithiation and delithiation processes due to its alloying mechanism [17, 18]. The huge volume change of silicon anode would cause disintegration and pulverization of the active material, causing poor electronic conductivity and an unstable SEI layer formation [19]. The poor electronic contact between active 


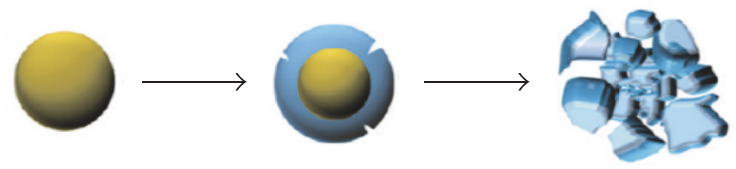

FIgURE 1: The fracture and crack of silicon during lithiation [31]. Copyright 2012 American Chemical Society.

material and conductive additives, as well as the accumulative SEI layer, can cause dramatic capacity fade, low Coulombic efficiency, and eventually failure of the cells [20,21]. A failure mode of micro-sized silicon anode was proposed by Ryu et al. The initial specific capacities of alloying and dealloying processes of the silicon based anode can reach $3260 \mathrm{mAh} / \mathrm{g}$ and $1170 \mathrm{mAh} / \mathrm{g}$, respectively, resulting in a low Coulombic efficiency of $35 \%$ [22]. After 10 cycles, the capacity of charge process fades to approximately $200 \mathrm{mAh} / \mathrm{g}$ with a retention of $6.1 \%[22]$.

Low-dimensional structures of silicon have been introduced and tested for better electrochemical performances [2, 23-26]. A great number of works have demonstrated the success of utilization of the low-dimensional structures in terms of the better electrochemical stability and enhanced rate performance [23, 27-30]. The smaller dimension structures compared with the bulky silicon have shown several improved characteristics for better electrochemical performances as investigated in the previous research: lowdimensional silicon anode materials maintain larger surface area; thus the fast electron transfer and shortened lithium diffusion pathway would be allowed for better rate performance; also, the smaller sizes of silicon could provide better accommodation with volume changes for better electrochemical stability [31-39]. In this review, different lowdimensional structures $(0 \mathrm{D}, 1 \mathrm{D}$, and $2 \mathrm{D})$ synthesized from various fabrication methodologies with enhanced electrochemical behaviors would be listed and discussed.

\section{Synthesis and Application of Silicon Particles}

2.1. Silicon Nanoparticles. In terms of suppressing the volume change of silicon based anodes, altering the morphologies and crystal structures of silicon is believed to be a useful approach. Nanosized silicon particles have shown promising potential for being next generation anode material of LIBs [40-42], which are commercially available. The nanospherical structures of $\mathrm{Si}$ can relax the stress generated from the volume change during cycles and possess more free room surrounded. Moreover, the chemical synthetic methods have been rather mature, and much superior electrochemical performance has been achieved from those approaches after a long time of investigation (Figure 2).

2.1.1. Hollow Structured Silicon. Silicon hollow nanoparticle is an interesting structure of silicon nanoparticles because it provides inner space allowing silicon to expand its volume both externally and internally [43]. In 2007, a nest-like silicon nanoparticle was reported with a reversible lithium storage
TABLE 1: Volume change induced by Li atom for the Li-Si system $[11,17]$.

\begin{tabular}{lcc}
\hline Phase & $\begin{array}{c}\text { Volume per } \\
\text { Si atom }\left(\AA^{3}\right)\end{array}$ & $\begin{array}{c}\text { Volume change } \\
\text { induced per Li } \\
\text { atom }\left(\AA^{3}\right)\end{array}$ \\
\hline $\mathrm{Si}$ & 20 & - \\
$\mathrm{Li}_{7} \mathrm{Si}_{2}$ & 67.3 & 13.5 \\
$\mathrm{Li}_{12} \mathrm{Si}_{7}$ & 58 & 22.4 \\
$\mathrm{Li}_{13} \mathrm{Si}_{4}$ & 67.3 & 14.6 \\
$\mathrm{Li}_{14} \mathrm{Si}_{6}$ & 51.5 & 13.7 \\
$\mathrm{Li}_{22} \mathrm{Si}_{5}$ & 82.4 & 14.2 \\
\hline
\end{tabular}

of $3952 \mathrm{mAh} / \mathrm{g}$ at $100 \mathrm{~mA} / \mathrm{g}$ and a ratability of $3052 \mathrm{mAh} / \mathrm{g}$ at $2000 \mathrm{~mA} / \mathrm{g}$ [44]. The synthesis was based on a solvothermal method in which sodium silicide $(\mathrm{NaSi})$ and ammonium bromide $\left(\mathrm{NH}_{4} \mathrm{Br}\right)$ [44] were involved as reacting agents to generate silicon while $\mathrm{LaNi}_{5}$ was adopted to absorb the hydrogen as by-product. The reactions could be described as [44]

$$
\begin{gathered}
\mathrm{NaSi}+\mathrm{NH}_{4} \mathrm{Br} \longrightarrow \mathrm{NaBr}+\mathrm{NH}_{3}+\mathrm{Si}+\frac{1}{2} \mathrm{H}_{2} \\
\mathrm{LaNi}_{5}+\mathrm{H}_{2} \longrightarrow \mathrm{LaNi}_{5} \mathrm{H}_{1 \sim 6} .
\end{gathered}
$$

In 2011, Yao et al. reported an interconnected silicon hollow sphere electrode with an initial discharge capacity of $2725 \mathrm{mAh} / \mathrm{g}$ and a retention of $52.1 \%$ after 700 cycles [45]. The Coulombic efficiency in later cycles reached to $99.5 \%$ at C/2 [45]. Those interconnected hollow silicon nanoparticles were synthesized through a template method [45]: nanosilica-particle precursors were firstly drop-coated on stainless steel substrate and coated with silicon by adopting chemical vapor deposition (CVD) of $\mathrm{SiH}_{4}$; then the hollow silicon nanoparticles were obtained by etching away silica with dilute HF. The characterization results and the synthesis procedures are shown in Figure 4. From the SEM and TEM results, hollow silicon particles with a diameter in nanometer scale were proved (Figure 3) [45].

2.1.2. Porous Silicon. Porous structure is another useful form of silicon nanoparticles which could provide free space for volume expansion of silicon and short path-length for lithium ions to diffuse [55]. Recently, Ge et al. [55] proposed a scalable method to synthesize silicon porous nanoparticles by using a two-step doping and etching process. The silicon nanoparticles were firstly mixed and annealed with boric acid in doping phase; then the system was etched by $\mathrm{HF}$ and silver nitrite to generate the porous structure of silicon nanoparticles [55]. This material also showed improved electrochemical performance. The specific capacity of this silicon porous nanoparticle could stabilize at $1000 \mathrm{~mA} / \mathrm{h}$ after 200 cycles at $\mathrm{C} / 2$.

2.1.3. Silicon Nanoparticle/Carbon Composite. The approaches discussed above did provide better electrochemical performance compared with silicon bulk crystal anodes, yet the 


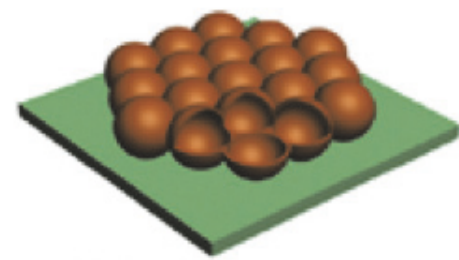

(a)

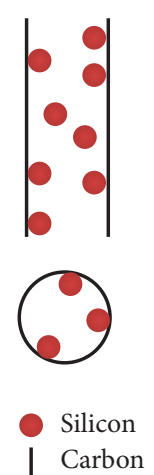

(b)

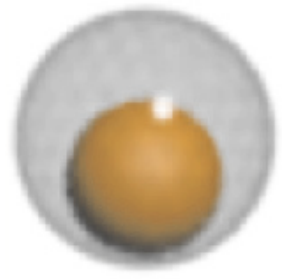

(c)

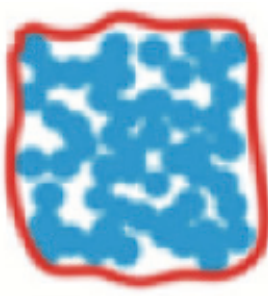

(d)

FIGURE 2: Recent development of 0D silicon structures. (a) The hollow structured silicon. (b) The carbon tube trapped silicon nanoparticles. (c) The core-shell structure of silicon nanoparticles. (d) The carbon coated silicon porous microparticles. Reprinted with permission [45-48]. Copyright 2011, 2012, 2015 American Chemical Society.

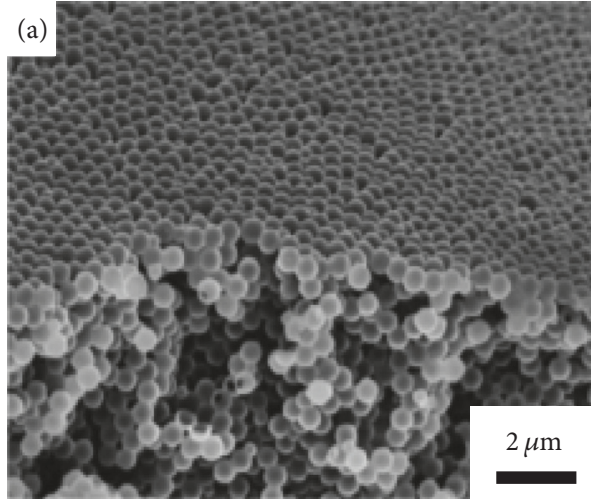

(a)

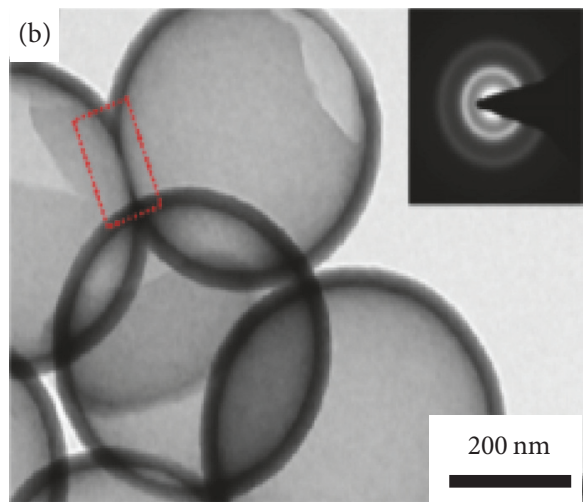

(b)

FIGURE 3: SEM (a) and TEM (b) images of the silicon hollow nanoparticles. Reprinted with permission [45]. Copyright 2011 American Chemical Society.

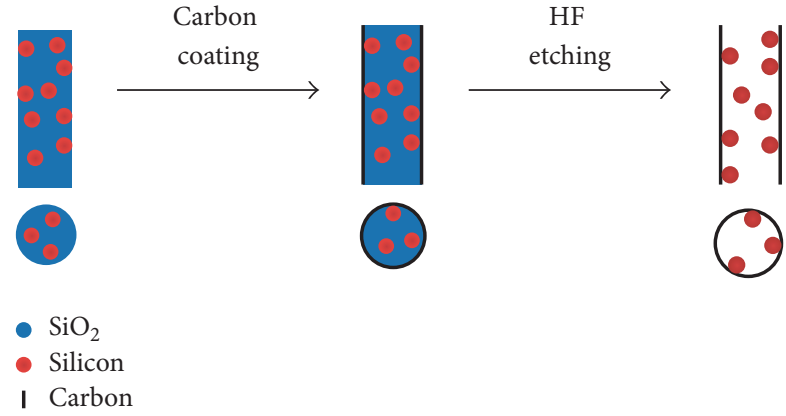

Figure 4: Schematic illustration of the synthesis of the carbon tube trapped silicon. Reprinted with permission [46]. Copyright 2012 American Chemical Society.

chemical synthetic routes were high-cost and nonscalable. Moreover, clear accumulation of SEI layer formation could be seen through these methods. Carbon coating is believed to be a useful protective layer material because of its soft and compatible nature as well as good conductivity, which could help with formation of stable SEI layer and promote electronic conductivity $[48,56]$.
In 2012, Wu et al. [46] reported a facile and scalable synthetic approach where silicon nanoparticles were mechanically produced and trapped in hollow carbon tube. The commercial silicon nanoparticles were firstly well mixed in TEOS solution, by serving as the silicon dioxide precursor. Then a low-cost and widely used electrospinning technique was adopted to generate silicon dioxide nanofibers containing silicon nanoparticles through the prepared solution system. After carbonization of the polystyrene coating and etching by $\mathrm{HF}$, the sparsely packed silicon nanoparticles trapped in hollow silicon tube were obtained. In this design [46], hollow space between carbon tube and silicon nanoparticles was provided for volume expansion of silicon. This structure exhibited a gravimetric capacity of $1000 \mathrm{mAh} / \mathrm{g}$ and maintained $90 \%$ thereof in 200th cycle [46].

Some other interesting structures of nano-silicon-carbon composite material have been proposed. Among them, a protective layer covered silicon nanoparticles showed great potential to address the severe capacity fade and low Coulombic efficiency of silicon based anode material for the following reasons [57-59]: first, a protective layer could leave some free room between silicon and the coating, providing proper 


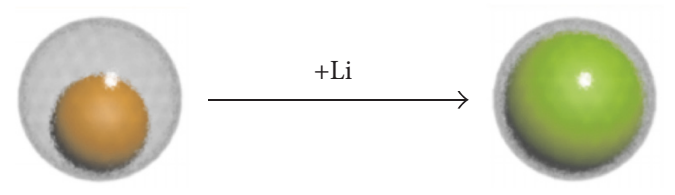

FIGURE 5: Schematic illustration of yolk-shell structure. Reprinted with permission [47]. Copyright 2012 American Chemical Society.

space for volume expansion of silicon. Also, a confined layer could restrict the pulverization process of silicon, contributing to the integration of the anode material. Moreover, a complete and conductive layer could efficiently minimize the direct electrode-electrolyte contact and enhance the electronic conductivity of anode material, leading to a better electrochemical performance. In 2012, Liu et al. [47] proposed a yolk-shell structure through low-cost precursors and scalable approach. The commercially available silicon nanoparticles were coated by solution-phase silica layer and polydopamine layer orderly in order to have a conformal and homogeneous coating [47]. Later the silica layer was etched away by $\mathrm{HF}$ and the polymer layer was carbonized to nitrogen doped carbon shell, leaving a conformal and complete carbon shell coated silicon nanoparticle with free void space [47]. This material achieved an initial capacity of $2800 \mathrm{mAh} / \mathrm{g}$ at $\mathrm{C} / 4$, a retention of $74 \%$ after 1000 cycles, and a Coulombic efficiency of $99.84 \%$, resulting from a complete, conformal, and self-supporting carbon shell, which could get rid of the direct contact between electrolyte and electrode, leading to a more stable SEI layer and less side reactions (Figure 5) [47].

In 2014, a novel structure composed of carbon shell coated silicon nanoparticles was reported by Liu et al. [60]. Their work was inspired by the structure of pomegranate, in which a large quantity of yolk-shell structures was closely packed, forming a pomegranate structure consisting of silicon nanoparticle, conformal and complete carbon shell, and the void space in between [60]. The synthesis approach was similar to that of yolk-shell structure, where a silica solutionphase layer and a polymer layer to be carbonized were involved. In order to obtain the pomegranate-like structure, an additional evaporation-driven self-assembly was added. This structure, explained by authors [60], could extremely minimize the electrolyte-electrode contact area and side reactions of electrolyte and promote the electronic connectivity with conductive additives, leading to a much stable electrochemical performance ( $97 \%$ capacity retention after 1000 cycles) and high volumetric capacity $\left(1270 \mathrm{mAh} / \mathrm{cm}^{3}\right)$.

The size effect of silicon nanoparticle based anode material has been investigated [61-63]. Liu et al. reported the study of lithiation of silicon nanoparticles by the in situ TEM microscopy. A threshold size of $150 \mathrm{~nm}$ for silicon nanoparticles was found. Silicon nanoparticles would not crack or fracture during the first lithiation with a diameter below $150 \mathrm{~nm}$ and would generate cracks during first lithiation with a diameter over $150 \mathrm{~nm}$ [31]. This phenomenon was explained by a two-phase model proposed by the authors, in which the inner core of the lithiated silicon would remain as crystalline phase and the outer shell would become the amorphous Li-Si alloy. The size-dependence is contributed by the insufficient amount of hoop tension to form the cracks in the small-sized silicon nanoparticles [31].

Ma et al. proposed a critical size for silicon nanoparticles of $\sim 90 \mathrm{~nm}$ based on the order-length-strength (BOLS) correlation mechanism $[64,65]$, below which the fracture would not be formed and above which the crack would occur during lithiation [66]. Kim et al. proposed a work comparing different small silicon nanoparticles. Silicon particles with $10 \mathrm{~nm}$ diameter showed the higher charge capacity, lower Coulombic efficiency, and a lower capacity retention of $81 \%$ compared with the ones with diameters of $20 \mathrm{~nm}$ [67]. After being coated with carbon, the $10 \mathrm{~nm}$ sized silicon nanoparticles showed improved Coulombic efficiency and capacity retention [67].

Magnesiothermic reduction method is a widely used approach to synthesize silicon based anode materials [68-71]. For instance, Xie et al. reported a porous silicon nanoparticle formation through magnesiothermic reduction synthesis by using the monodisperse silica sphere as stating material [72]. The reduction process is shape-preserving and providing a well-dispersed silicon spherical template for further carbon coating process, which helps exhibit a good electrochemical performance. The magnesiothermic reduction method is a facile and scalable synthesis method to reduce prepared silica template to the desired shape-preserving silicon material. Also, compared with carbothermal reduction approach, the temperature employed in the magnesiothermic reduction is much lower $\left(\sim 650^{\circ} \mathrm{C}\right)[73]$.

However, few limitations have restricted the further application of silicon synthesis. For example, the original structures of silica template would be well preserved during the magnesiothermic reduction process, which indicates that the reduction procedure would have no contribution to the structural formation of the silicon, requiring an extra novel structure preparation of silica precursors [74]. The reduction agent, metallic magnesium, would be melted under $\sim 650^{\circ} \mathrm{C}$ during the reduction process, leading to an incomplete reduction of silica. The etching process of the unreacted silica often requires the participation of $\mathrm{HF}$, which is extremely dangerous and unenvironmentally friendly.

2.2. Silicon Microparticles. As has been investigated above, silicon nanostructures synthesized from various methodologies exhibited improved electrochemical performance including higher reversible capacity, longer cycle life, and better high-rate capability due to the size effect and unique structures. However, the better electrochemical performance of silicon nanoparticle anodes is achieved though low mass loading of active material, leading to a low volumetric capacity. Also, a large portion of synthetic routes [44, 45, 47] to produce silicon nanostructures was involved with highcost and nonscalable techniques, making it nonaccessible for industrial applications. In contrast, silicon microparticles are already commercially available and of low-cost.

Various methodologies to produce silicon microparticles for lithium ion battery application have been conducted and tested. In 2007, Bao et al. [73] produced silicon porous microstructure by adopting a magnesiothermic reduction 


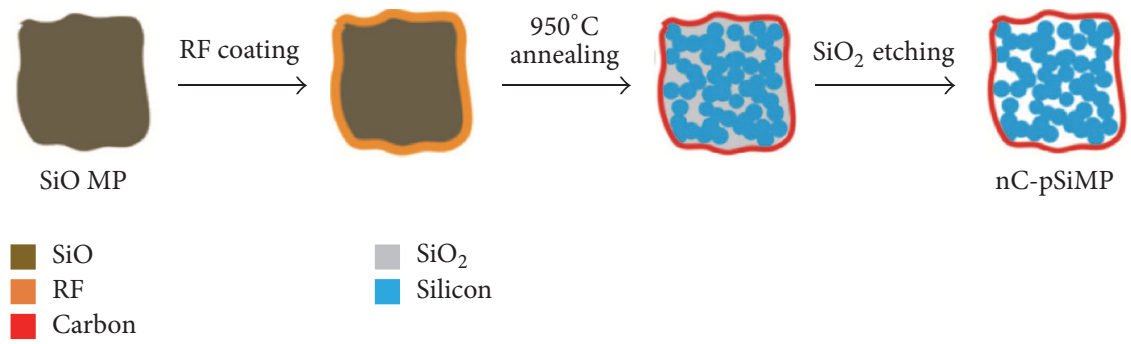

FiguRE 6: Schematic illustration of the synthesis of the nonfilling carbon coated silicon. Reprinted with permission [48]. Copyright 2015 American Chemical Society.

process with a high specific surface area and a highly porous three-dimensional structure for various application including sensors, electronics, and optical and biomedical utilizations. In 2013, Wang et al. [75] adopted hydrogen-bonding selfhealing polymer material as coating to pack silicon microparticles for stable and deep galvanostatic cycling. Compared with traditional polymer binder material as polyacrylic acid (PAA), the damage in the electrode caused during cycling could be automatically repaired by the predesigned selfhealing function [75]. The anode achieved a retention of $80 \%$ of the initial capacity after 90 cycles, which was more than ten times longer than those of all the other silicon microparticle electrodes [75].

Later, Lu et al. [48] proposed a novel model where porous silicon microparticles were covered by a nonfilling carbon coating through cheap precursors and mild synthetic approach. Commercial silicon monoxide microparticles were first coated by resin coating and annealed under high temperature so that a two-phase structure occurred through the disproportionation of silicon monoxide forming interconnected silicon nanoparticles surrounded by silicon dioxide matrix and resin coating which were converted to carbon coating in the meantime [48]. After etching of HF, the micro-sized silicon porous particles covered by nonfilling carbon coating was obtained [48]. The synthetic route is shown in Figure 6. This work is comparably scalable and of low-cost resulting from the commercially available precursors and simple step to obtain silicon monoxide and carbon coating conversion spontaneously. As a result [48], this structure obtained a specific reversible capacity of $1500 \mathrm{mAh} / \mathrm{g}$ after 1000 cycles at $\mathrm{C} / 4$ with a mass loading of $0.614 \mathrm{mg} / \mathrm{cm}^{2}$. The structure also showed a stable areal capacity of $3 \mathrm{mAh} / \mathrm{cm}^{2}$ with a high mass loading of $2.01 \mathrm{mg} / \mathrm{cm}^{2}$ [48], which fully addresses the low mass loading problem of silicon nanoparticle anodes.

A size effect of silicon-carbon micro-sized composite anode material was reported. Yi et al. found a threshold size of $15 \mathrm{~nm}$ for the silicon nanoblocks building up the silicon microparticles [76]. The silicon microparticles comprising silicon nanoblocks with critical size and carbon coating showed high capacity and improved electrochemical stability [76].

\section{Synthesis and Application of Silicon Nanotubes and Fibers}

3.1. Silicon Nanotubes. Silicon nanotubes are another exciting structure of silicon which has been applied and tested in various fields including lithium secondary cells and other nanoelectrochemical devices [77-80]. In LIBs study, silicon nanotube has drawn a lot of attention due to its unique hollow structure which could provide both inner and outer space for silicon to expand during cycling, minimizing the cracks and damage to the anode. What is also contributing is the shorter path-length and large surface area offered by the thin wall of silicon nanotubes. These advantages are believed to make silicon nanotube promising for further application and study.

3.1.1. Template Assisted Synthesis of Silicon Nanotubes. At the initial stage of silicon nanotube study, templates were introduced to assist the synthesis of nanotube structure. In 2002 , the nanotube structure of silicon was firstly synthesized by Sha et al. through an anodized alumina with nanochannel template assisted method. Silane gas was decomposed by chemical vapor deposition (CVD) method and deposited on the surface of nanochannels of the anodized alumina [81]. Later, multiple silicon nanotubes fabricated by template assisted methods were reported and applied for lithium ion battery. In 2009, Park et al. prepared silicon nanotube by another anodized alumina template assisted method. The silicon precursor, $\mathrm{SiCl}_{4}$, was reduced and deposited into the anodized alumina template with pore diameters of 200-250 nm [23]. After being coated with carbon, this silicon nanotube composite material was tested as half-cell and showed outstanding reversible performance. The reversible charge capacity could reach $3648 \mathrm{mAh} / \mathrm{g}$ and a retention of $89 \%$ at $0.2 \mathrm{C}$ [23]. This outstanding electrochemical performance was attributed to the unique tubular silicon structure and the carbon coating which could avoid forming accumulative SEI layers.

Various forms of templates were utilized to fabricate silicon nanotubes. In 2010, Song et al. adopted zinc oxide as template material to synthesize arrays of sealed silicon nanotubes. The synthetic routes consist of three steps [27]: the zinc oxide rods were grown on the sacrificial template material by a hydrothermal reaction. Then silicon layer was coated by decomposing silicane through a CVD method on the zinc oxide rods template. In the end, a high temperature reduction process was introduced to remove the zinc oxide template and form the sealed silicon nanotubes. This structure exhibited a high initial Coulombic efficiency of $85 \%$ and a stable cycling performance of retention of $80 \%$ after 50 cycles, resulting from the additional void space provided by the inner empty room of the structure [27]. Moreover, the 
mechanical tests of this structure during lithiation indicated a huge anisotropic volume expansion with $400 \%$ volumetric increase of the surfaces area while only a $35 \%$ expansion was found in the axis dimension, which provided a general guideline for the following study [27].

In 2012, a feasible organic nanowires assisted silicon nanotubes fabrication method was reported by Yoo et al. This synthetic method could be generalized into four steps [78]: polyacrylonitrile (PAN) nanofibers synthesized from electrospinning were converted into pyridine fibers through air pyrolysis. Then the obtained pyridine fibers were coated with another tetraethyl orthosilicate (TEOS) layer. Later the pyridine fibers served as template were removed to have silicon dioxide nanotubes. Finally, after the magnesium reduction and graphitic carbon coating, the silicon nanotube covered by carbon shell would be ready for further tests. In electrochemical tests, the obtained structure showed stable performance compared with commercial silicon nanoparticle anodes: an initial capacity of $1900 \mathrm{mAh} / \mathrm{g}$ at $400 \mathrm{~mA} / \mathrm{g}$ and a Coulombic efficiency of $\sim 98 \%$ [78]. This work proposed a comparably scalable and low-cost synthesis method compared with former template assisted approaches, which can make a step forward to the larger scale production of silicon nanotubes. A similar synthesis route was reported by Wen et al. via utilizing rod-like $\mathrm{NiN}_{2} \mathrm{H}_{4}$ as template and a thermal reduction process [82].

The hollow structure of silicon nanotubes can provide an inner space for silicon to expand during lithiation, yet as discussed above, silicon nanotube can undergo a volume expansion with $400 \%$ volumetric increase, resulting in a SEI layer crack during the shrinkage of silicon, finally leading to an accumulation of SEI. The unstable SEI formation can directly cause the cell failure resulting from [83]: the accumulated SEI formation can continuously consume lithium ions and electrolyte; the insulating thick SEI layer could restrict the electronic conductivity of conductive additives and anode materials while creating a long pathway for lithium diffusion; also the mechanical stress from the thick SEI layer could cause electrode material degradation. Based on these explanations, a confined layer structure which could provide the pathway for ion diffusion and enough mechanical strength to restrict the volume change of silicon is needed for silicon nanotube structures to be further applied in anode material study.

In 2012, Song et al. reported a Si/Ge double-walled nanotube with improved capacity and stability with respect to bulk silicon anodes. In their design, zinc oxide nanorods fabricated from hydrothermal reaction were utilized as template material and coated by silicon layer through CVD method. After etching away the zinc oxide nanorods, Ge layer was coated outside of the silicon nanotube through CVD method by adopting germane gas as precursor [49]. The obtained structure could be seen in Figure 7 . The electrochemical tests of the structure showed stable capacity retention of $85 \%$ after 50 cycles at $0.2 \mathrm{C}$ and doubled capacity at the rate of $3 \mathrm{C}$ [49]. The electrochemical stability and ratability are contributed by the mechanical strength and easy diffusion pathway provided by the Ge layer. Moreover, this work has proved that the group IVA/silicon nanocomposite structures are promising for future investigation and application of anode material.

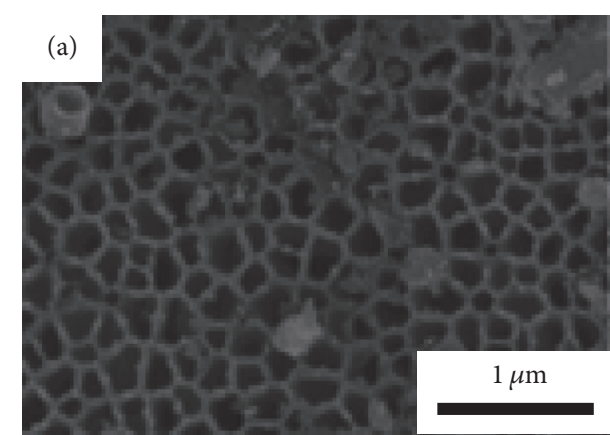

(a)

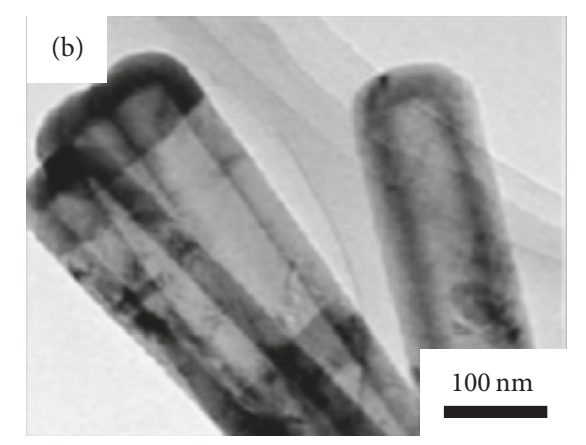

(b)

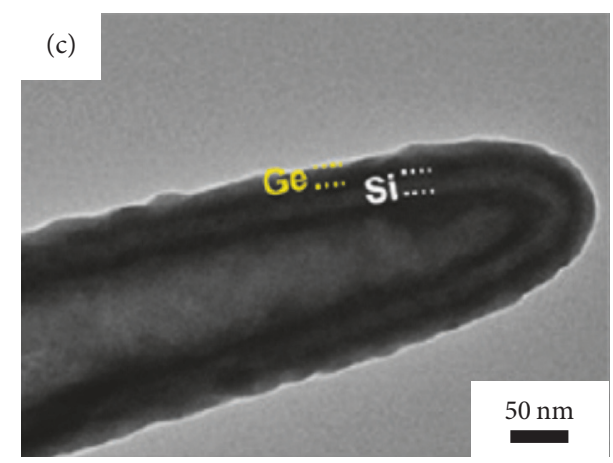

(c)

FIGURE 7: Recent development of 1D silicon nanotubes. (a) The unsealed silicon nanotube array. (b) The sealed single-layered silicon nanotubes. (c) The sealed double-layered silicon nanotubes [23, 27, 49]. Copyright 2009, 2010, 2012 American Chemical Society.

Another carbon group element was chosen to form double-walled structure with silicon by $\mathrm{Wu}$ et al. In their design [83], electrospun polymer fibers were firstly precarbonized and coated silicon through a CVD process. Then the heterostructure was annealed in air to oxidize carbon into carbon dioxide gas and form $\mathrm{SiO}_{x}$. Thus a double-walled structure consisting of inner silicon wall and outer silicon oxide wall was obtained. This structure showed exciting stable electrochemical performance [83], where retentions of $93 \%$ and $88 \%$ of initial capacity were recorded after 4000 and 6000 cycles, respectively, at $10 \mathrm{C}$. The outer layer of silicon oxide provided an accessible pathway for ion diffusion while providing mechanical strength to restrict the volume expansion of silicon, contributing a stable and thin SEI formation. However, the initial Coulombic efficiency was 


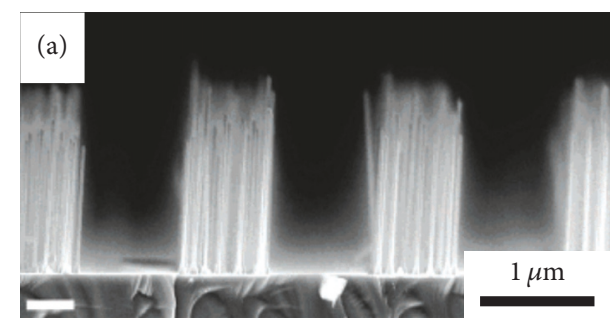

(a)

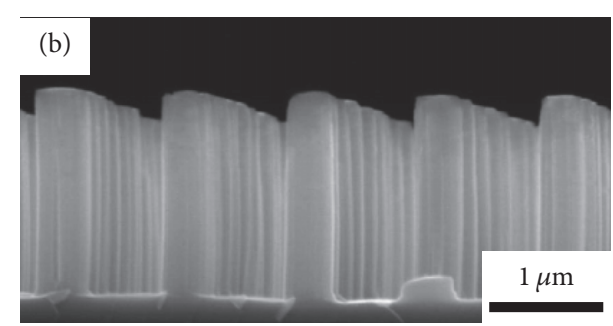

(b)

Figure 8: Recent development of 1D silicon nanowires. (a) The nanowires synthesized from bottom-up methods. (b) The silicon nanowires synthesized from top-down method [50-52]. Copyright 2005, 2008 American Chemical Society.

only $76 \%$ due to the constraining force of silicon oxide layer and the consumption of lithium ions during the SEI layer formation [83].

As has been investigated above, silicon nanotube structures have exhibited improved electrochemical performance compared with silicon bulk anodes. However, template assisted synthesis approaches of silicon nanotubes are still complicated and nonscalable due to the multiple steps of the synthesis route and the high-cost techniques. Great efforts are still needed to address these restrictions.

3.1.2. Template-Free Synthesis of Silicon Nanotubes. Recently, template-free methods have been developed. In 2005, a hydrothermal reaction involved method was introduced by Chen et al. to fabricate silicon nanotubes [77]. The starting material, silicon monoxide, and deionized water were firstly mixed in kettle and underwent two steps: in the beginning were the decomposition of silicon monoxide and the nucleation of silicon nanotube; then the silicon nanotube growth process started. It was a self-assembly process, generating silicon nanotube structure with smaller dimension and purer phase compared with traditional template-involved synthesis. Another template-free synthesis route to produce silicon nanotube was proposed by Castrucci et al., in which direct current-arc method was introduced to produce the nanotube structure with small dimension [84]. The methodologies mentioned above could generate silicon nanotube structures without participation of template, yet the low mechanical strength and tiny dimension of the nanotubes restrict them for further anode application of lithium ion battery.

In summary, silicon nanotube based anode material has shown improved stability and high-rate capability compared with conventional silicon bulk anodes. The unique mechanical behavior and short ion diffusion pathway of the nanowalls make it helpful to form a stable SEI layer during cycling, leading to an improved electrochemical stability. However, the low volumetric capacity resulting from hollow structure and porous nature of silicon nanotubes, together with the nonscalable synthesis routes, is severely minimizing their possibility of further commercial application. Hence, mild and facile synthesis is required for future application.

3.2. Silicon Nanowires. The successful synthesis of silicon nanowire was firstly reported in late 1950s [85]. Since then, various synthesis methods were studied and reported to fabricate silicon nanowires with desired dimensions. Silicon nanowires, together with other nanoscale structures as nanoparticles and nanotubes, could relax the stress coming from volume change during cycling and restrain crack and pulverization of anode material due to their unique grain boundary dynamics $[28,86]$. Correspondingly, silicon nanowires have been applied in anode material study of LIB since 2007 with advanced and outstanding electrochemical performance $[83,87]$. Inspired by the mature synthesis approaches and promising electrochemical performance, more and more silicon nanowire structures are being studied and tested electrochemically (Figure 8).

3.2.1. Vapor-Liquid-Solid Synthesis of Silicon Nanowires. The vapor-liquid-solid (VLS) mechanism, a bottom-up method, is the most mature and widely used synthesis mechanism for silicon nanowire growth. Hochbaum et al. combined commonly used CVD technique to grow silicon nanofibers through VLS mechanism in 2005. In their work [50], vertically aligned and single-crystalline silicon nanowires were synthesized through CVD technique by adopting $\mathrm{SiCl}_{4}$ and gold colloids, which were served as silicon precursor and the seeding material, respectively. The diameters and density of the produced silicon nanowires could be precisely controlled by altering the diameter and solution concentration of the gold colloids. Moreover, the control of spatial distribution can be achieved by changing patterning region through the microcontact printing of the gold colloids.

Another CVD involved template assisted synthesis through VLS method with much higher packing density of wires was reported by Lombardi et al. In their work [88], gold loaded porous anodized alumina was annealed in furnace where silicane gas was introduced and formed well-ordered and closely packed silicon nanowires. After the removal of alumina template, vertically aligned nanowires supported on silicon substrate would be obtained [88]. The dimensions and packing density of the nanowires are controllable through adjusting the dimensions and density of pores in aluminum oxide template, which could be easily achieved [88]. These two methods mentioned above are involved with high temperature annealing $\left(\sim 800^{\circ} \mathrm{C}\right)$, when low temperature annealing via CVD technique was adopted, interesting phenomenon was observed. In 2004, the synthesis of single-crystalline silicon nanowires in few nanometers' 
scale was reported through CVD technique at $435^{\circ} \mathrm{C}$ [26], which was in much lower dimension than the previous work.

As was discussed above, a VLS mechanism based synthesis approach through CVD technique can precisely control the dimension, packing density, and spatial distribution of the obtained silicon nanowires. Inspired by the mature and successful synthesis method, electrochemical application of the silicon nanowires has been investigated. In 2007, Chan et al. successfully applied silicon nanowires to LIB application through a CVD method. After the synthesis, vertically aligned silicon nanowires supported by stainless steel substrate were tested electrochemically [2]. This structure exhibited an improved initial Coulombic efficiency of $73 \%$ and high-rate capability [2]. The 2D structure can endure expansion and shrinkage of silicon without nucleation or propagation of the cracks or pulverization of anode. Also, the $1 \mathrm{D}$ geometry is believed to greatly promote the electronic conductivity between active material and conductive additives and shorter ionic pathway [89-92]. However, the Coulombic efficiency showed was still low mainly resulting from the unstable and accumulated SEI layer formation on the outer layer of the silicon nanowires. Hence, in order to address the challenge mentioned, a lot of work has been reported. Silicon nanowires covered with carbon coating were prepared by Chen et al. In their work [93], the silicon nanowires coated by a conductive and mechanically rigid carbon coating showed improved initial Coulombic efficiency of $83 \%$ and a capacity retention of $75 \%$ in 15 th cycle.

As was discussed previously, carbon coating can enlarge the electronic conductivity and minimize the electrolyteelectrode contact area, resulting in a stable and thin SEI layer and therefore a more stable electrochemical performance compared with bulk silicon anodes. Conductive polymer coating was also employed to silicon nanowire study. If compared with silicon nanoparticle based anode material, the electrochemical stability of silicon nanowires is still quite low due to the detachment of nanowires from the substrate during volume expansion [94]. In order to address this limitation, Nguyen et al. proposed a novel synthesis methodology to fabricate interconnected silicon nanowires, where plasma-enhanced CVD (PE-CVD) was involved. In their work [94], highly interconnected and entangled silicon nanowires were produced, which could largely restrict the detachment of individual nanowires when excess stress was applied at the root during lithiation. The desired structure did show enhanced electrochemical stability. A capacity retention of $100 \%$ after 40 cycles at C/2 and a retention of $90 \%$ after 70 cycles at $2 \mathrm{C}$ were reported [94]. Moreover, through the PE-CVD methodology, a high load of silicon of $1.2 \mathrm{mg} / \mathrm{cm}^{2}$ and a high areal capacity of $4.2 \mathrm{mAh} / \mathrm{cm}^{2}$ were achieved [94], contributed by the interconnected nanowire structures.

As was mentioned, the VLS method with CVD is a mature and widely employed approach to synthesize silicon nanowires with precisely controlled dimension and distribution. The structures fabricated from VLS method have shown improved and promising electrochemical stability and highrate capability. However, few limitations have restricted this method from further academic and industrial applications.

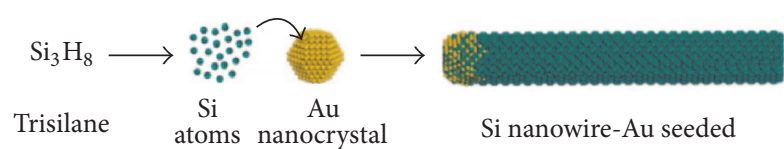

FIGURE 9: Schematic illustration of the SLS growth of the silicon nanowires. Reprinted with permission [51]. Copyright 2008 American Chemical Society.

First of all, all CVD involved methods including the VLS mechanism suffer from the high-cost and low yield nature, largely minimizing the potential of silicon nanowires for scalable synthesis. Also, the silicon nanowires synthesized from VLS methods require support from substrate material, easily forming side reactions and metal silicates from the nanowire and substrate contact [95], leading to capacity fade. Thus more efforts are demanded to counter these restrictions.

3.2.2. Solution Based Synthesis of Silicon Nanowires. Solution based synthesis approach, also a bottom-up method, is a high-yield methodology compared with the bottom-up method. The first solution based method to produce silicon nanowires was reported by Korgel's research group in 2000 . In their work [96], a "supercritical-fluid-liquid-solid" (SFLS) method was adopted, in which silicon nanowires start to grow on the surface of the alkanethiol coated gold nanocrystals when the concentration of silicon precursor solution becomes saturated. The saturation process is controlled by the applied heat and pressure. Due to the participation of supercritical of liquid, the fabricated silicon nanowires are coated with a thin chemisorbed polyphenylsilane shell [51, 97-99]. A large yield of detect-free microscale silicon nanowires was obtained with uniform diameter distribution [96]. Parallel with the VLS method, the SFLS method requires participation of catalyst like $\mathrm{Au}$ and possesses the nature to control the orientation of produced silicon nanowires [96, 99]. Unlikely, the liquid phase silicon precursor and gold nanocrystal dissolved supercritical liquid system is able to deliver a high-yield and defect-free silicon nanowire production in high pressure and temperature. Inspired by this work, the solution-liquid-solid method (SLS) was proposed later [51]. In 2008, Heitsch et al. employed organic solvent instead of supercritical liquid to fabricate high-yield microscale silicon nanowires with diameters of $\sim 25 \mathrm{~nm}$ in the presence of $\mathrm{Au}$ or Bi nanocrystals under atmospheric pressure (Figure 9) [51].

In 2010, silicon nanowire anode based on SFLS for lithium ion battery method was reported by Chan et al. In their work, silicon nanowires with a yield of $45 \mathrm{mg} / \mathrm{h}$ were mixed with carbon conductive additives and tested electrochemically [98]. However, huge capacity fade occurred during the galvanostatic charge and discharge test. The initial capacity of $1077 \mathrm{mAh} / \mathrm{g}$ and a retention of $14 \%$ after 75 cycles were achieved [98]. It was explained that the polyphenylsilane shell chemisorbed of the silicon nanowires prohibited electronic connectivity between active material and the conductive additives [98]. To address the poor electronic conductivity caused by polyphenylsilane shell, Chokla et al. employed an additional thermal annealing process to convert the 
polymer coating with poor conductivity to the carbonaceous layer. In their work, the silicon nanowires synthesized from the mature SFLS method with polyphenylsilane shell were annealed in titanium reactor under $490^{\circ} \mathrm{C}$ and a high pressure of 10.3 MPa [97]. Afterwards, crystalline silicon nanowires with diameters in tens of nanometer scale and length in microscale were obtained, which indicated that the additional thermal annealing process did not cause any damage to the structure of silicon nanowires [97]. Correspondingly, an improved initial capacity retention of $54 \%$ after 100 cycles was obtained [97]. In general, solution based synthesis can provide high-yield silicon nanowires, yet the electrochemical performance is limited by the inactive residual and unstable SEI layer formation. In order to have better electrochemical performance of this structure, revised and modified synthesis routes are demanded.

3.2.3. Top-Down Synthesis of Silicon Nanowires. Differentiating from bottom-up synthesis, conventional top-down approach consists of the patterned silicon substrate fabrication and the following etching process. In 1993, Liu et al. reported yielded silicon nanowires with self-limiting diameters of less than 10 nanometers [100]. The synthesis route consists of electron-beam lithography and self-limiting oxidation reaction etching process to generate nanofibers [100]. Later, multiple patterned silicon substrate fabrication methods were introduced and tested [52, 101-103]. When the obtained structure is tested as anode for lithium ion battery study, the two-step top-down synthesis methods are less popular due to the complicated and nonscalable procedures. Therefore, a one-step electroless-etching process is more widely adopted. Peng et al. reported metal-induced electroless etched silicon nanowires with good conductivity. In their work, a large area of silicon nanowire arrays in waferscale was produced through the metal-induced chemical etching process directly from the original silicon wafer [104]. Therefore the obtained rough silicon nanowires would inherit the characteristics from the silicon wafer [104]. From the electrochemical results, large charge capacity and long cycling stability were obtained, contributed by the inherited electronic properties from silicon wafer and the large surface area of rough morphology [104]. Huang et al. proposed a carbon coated silicon nanowires array films. In their work, single-crystal $p$-type silicon wafers were electroless-etched by a HF based aqueous solution [105]. The carbon coating was achieved through annealing of carbon aerogel [105]. The obtained silicon nanowires exhibited an initial capacity of $3344 \mathrm{mAh} / \mathrm{g}$ and a Coulombic efficiency of $84 \%$ at $150 \mathrm{~mA} / \mathrm{g}$ [105]. A reversible capacity of $1326 \mathrm{mAh} / \mathrm{g}$ in 40th cycle was achieved [105]. This improved capacity and stability were resulting from the uniform and continuous carbon coating, providing better electronic conductivity and restriction of volume change [105]. A porous doped silicon nanowire structure synthesized from electroless etched method was reported. A boron doped silicon wafer was directly etched to generate the porous silicon nanowire [106]. After being mixed with the carbon black and alginate binder, the obtained structure was tested electrochemically. The half-cell based on the desired structure exhibited reversible capacity of 2000, 1600, and 1100 after 250 cycles at $2 \mathrm{~A} / \mathrm{g}, 4 \mathrm{~A} / \mathrm{g}$, and $18 \mathrm{~A} / \mathrm{g}$, respectively [106]. The outstanding electrochemical stability results from the novel porous structure of the doped nanowires, providing a better electronic contact between active material and conductive additives, a short ionic diffusion pathway, and enough void space for volume expansion [106].

The size effect of the fractures during the lithiation for silicon nanowires has been studied [17, 107]. Ma et al. reported a critical size of $\sim 70 \mathrm{~nm}$ for the fracture of silicon nanowires based on the BOLS correlation mechanism [66]. The silicon nanowires sized below $\sim 70 \mathrm{~nm}$ could avoid fractures and cracks during lithiation. McDowell et al. proposed a size effect of $\sim 50 \mathrm{~nm}$ for silicon/silicon dioxide nanowires [108]. In their work, silicon nanowires covered by native surface dioxide layer with diameters below $\sim 50 \mathrm{~nm}$ could suppress the volume expansion during lithiation, which was studied by ex situ TEM spectroscopy. Ryu et al. proposed that silicon nanowires with diameters below $300 \mathrm{~nm}$ would not fail during lithiation even though the occurrence of huge fractures and cracks, confirmed by in situ TEM spectroscopy.

In summary, silicon nanowires can be fabricated by multiple methods including VLS based method, solution based method, and etching from silicon wafers. The prepared silicon nanowires from these methods can provide advanced and improved electrochemical performance in terms of Coulombic efficiency and initial capacity compared with bulk silicon anode. However, the high-cost and complicated procedures in synthesis including annealing process by CVD and the utilization of high-cost precursors and metal catalyst largely limit the possibility for silicon nanowires from further industrial applications.

\section{Synthesis and Application of Silicon Thin Film}

Silicon thin film anode is one of the most successful silicon structures applied in lithium ion battery study. Its interesting film structure with high surface area and thin thickness can provide good electronic contact with conductive additives and short pathway for ionic diffusion [109-112]. The synthesis approach for thin film structure is already mature and widely used. Also, the simple structure of thin film can allow doping or alloying with other elements in synthesis process, providing potential for further academic and industrial electrochemical application. In this section, different methods for fabricating silicon thin film in lithium ion battery application and the corresponding characterization results would be exhibited and discussed (Figure 10).

4.1. Physical Synthesis of Silicon Thin Film. Physical methods to fabricate silicon thin film consist of physical silicon vaporization and deposition. Multiple physical vaporization techniques were employed and tested. Maranchi et al. reported a radio frequency (RF) magnetron sputtering involved approach to produce silicon thin film. In their work [113], amorphous silicon thin films with two kinds of thickness of $250 \mathrm{~nm}$ and $1 \mu \mathrm{m}$ were deposited on cupper foil through a RF magnetron sputtering of highly pure silicon source $(99.999 \%)$. Later X-ray diffraction (XRD) 


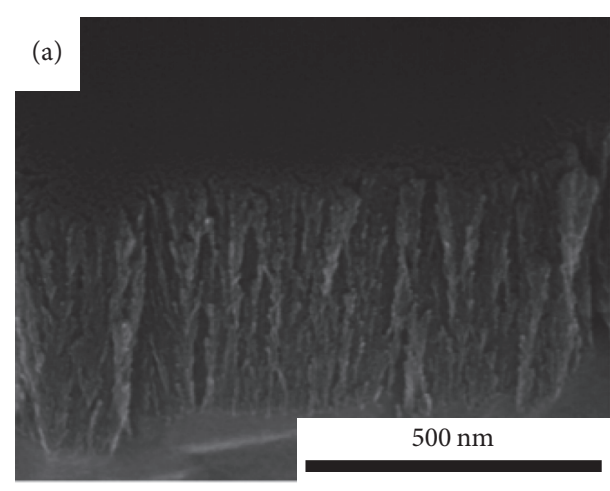

(a)

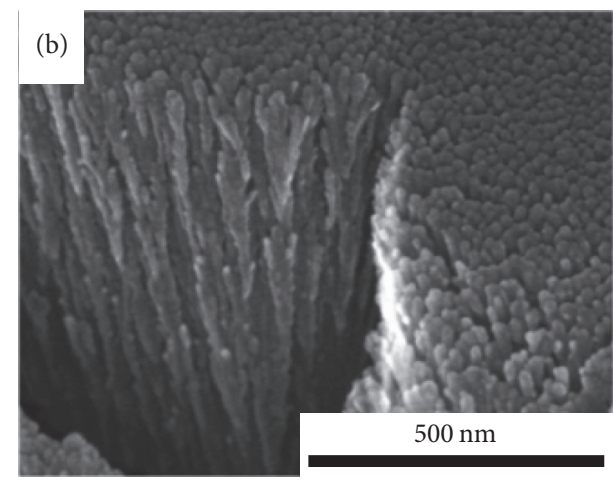

(b)

Figure 10: Recent development of 2D silicon thin films. (a) The silicon thin film. (b) The Si/Ge thin film [53, 54]. Copyright 2012, 2013 American Chemical Society.

and scanning electron microscopy (SEM) were adopted for composition and morphology characterization. The XRD result of the sample indicated the amorphous nature, which would contribute to the electrochemical stability resulting from the homogenous volume change during the cycling [113]. The following electrochemical results confirmed the former theory. The silicon thin film with a thickness of $1 \mu \mathrm{m}$ showed a reversible capacity of $3000 \mathrm{mAh} / \mathrm{g}$ for 12 cycles at $\mathrm{C} / 2.5$, while the film with a thickness of $250 \mathrm{~nm}$ exhibited a reversible capacity of $3500 \mathrm{mAh} / \mathrm{g}$ for 30 cycles at C/2.5 without obvious degradation [113]. The SEM results of the silicon thin film with $250 \mathrm{~nm}$ thickness after the electrochemical tests indicated the stable electrochemical performance resulting from the excellent adhesion of thin film to the conductive additives, the cupper foil [113]. Moreover, separate surface agglomerates with a diameter of $\sim 200 \mathrm{~nm}$ were found and explained to be the result of the cracked microstructures after the volume expansion and shrinkage, contributing to the irreversible capacity [113].

A comparison between amorphous silicon thin film and crystalline silicon nanoclusters was conducted by Graetz et al. The amorphous silicon thin film was produced by physical vapor deposition (PVD) method with a thickness of $100 \mathrm{~nm}$ [114]. The silicon thin film showed better electrochemical stability: an initial capacity of $3500 \mathrm{mAh} / \mathrm{g}$ and a reversible capacity of $2000 \mathrm{mAh} / \mathrm{g}$ after 50 cycles while the crystalline silicon nanoclusters exhibited an initial capacity of $1100 \mathrm{mAh} / \mathrm{g}$ with a retention of $50 \%$ after 50 cycles [114]. The improved electrochemical stability of both the amorphous silicon thin film and crystalline silicon nanoclusters were contributed by the smaller nanoscale dimension compared with silicon bulk crystals, leaving no possibility for domain dislocation [114]. Also, the improved electrochemical performance of amorphous silicon thin film was contributed by the larger contact area between the active material and conductive additives [114]. A composite thin film was reported by Song et al. In their work, crystalline $\mathrm{Mg}_{2} \mathrm{Si}$ thin film with a series of thickness from 30 to $380 \mathrm{~nm}$ was prepared through pulsed laser deposition (PLD) technique [115]. They found that the first cycle irreversible capacity loss increases with film thickness [115]. Correspondingly, the thinnest film with a thickness of $30 \mathrm{~nm}$ exhibited a reversible capacity of $2200 \mathrm{mAh} / \mathrm{g}$ after 100 cycles [115]. The enhanced electrochemical stability of the thin film results from their more amorphous character of thinner film, shorter ionic diffusion pathway provided by thinner thickness, and restricted grain volume expansion/shrinkage of two-dimensional structure [115].

4.2. Chemical Synthesis of Silicon Thin Film. Chemical synthesis approach of silicon thin film includes the vaporization and chemical change of silicon precursors as well as the deposition of pure silicon vapor. In 1999, Bourderau et al. employed chemical vapor deposition (CVD) method with silicane as precursor under $650^{\circ} \mathrm{C}$ to fabricate an amorphous silicon thin film with a thickness of $1.2 \mu \mathrm{m}$ [116]. The obtained thin film anode showed severe capacity degradation after three cycles, resulting from the crack and loss of active material during volume change related to the large thickness of the film [116]. A low-pressure chemical vapor deposition (LPCVD) involved synthesis was introduced by Jung et al. In their work, amorphous silicon thin film with a thickness of $50 \mathrm{~nm}$ was fabricated by using disilane through LPCVD [117]. The obtained structure achieved an initial capacity of $4000 \mathrm{mAh} / \mathrm{g}$ and an enhanced cyclability over 1500 cycles at $400 \mathrm{mAh} / \mathrm{g}$. Moreover, the structure was also tested as full cell with $\mathrm{LiMn}_{2} \mathrm{O}_{4}$ anode, showing an output voltage of 3.0-3.8 V and a cyclability of 400 cycles [117].

The size effect of avert fracture for silicon thin films has been studied $[118,119]$. Ma et al. reported the threshold size of $33 \mathrm{~nm}$ for silicon thin films, below which the nanostructures of silicon would avoid fractures during lithiation [66]. A critical size of $300 \mathrm{~nm}$ was proposed by Graetz et al. and high reversible capacity as well as improved electrochemical performance was obtained [114].

In general, silicon thin film has great potential for anode material application because of its unique two-dimensional film geometry, playing a role as an ideal supporter for doping or alloying process and a simple system for various characterization techniques [120, 121]. Furthermore, the large contact area and adhesion effect between active material and conductive additives and short pathway for ionic diffusion 
contributed by the unique structure has delivered high initial capacity and electrochemical stability. The study of the separate surface agglomerates occurring during lithiation/delithiation can help us better understand the cracking and decrepitation mechanism of silicon anode material [113, $122,123]$.

\section{Conclusion and Future Outlook}

In this review, the recent progress in synthesizing silicon nano-/microstructured materials for lithium ion battery anode study has been introduced and discussed. Silicon anode material, which is expected to be the next generation anode material for LIBs, has a high theoretical capacity of $4200 \mathrm{mAh} / \mathrm{g}$. However, the huge volume change of silicon resulting from the formation of lithium-silicon alloy during cycling has caused severe capacity degradation. Moreover, the semiconducting nature of silicon limits the conductivity of the anode material.

In order to solve the volume expansion/shrinkage issue and enhance the conductivity of the active material, multiple synthesis approaches have been proposed and discussed to fabricate silicon with useful geometry for better electrochemical performance. Typically, low-dimensional silicon structures, including nano-/micro-silicon particle (0D), tube and wire (1D), and thin film (2D), have drawn plenty of research interests due to their novel structures and small grain sizes. Small grain sizes of silicon can largely accommodate the volume change and provide enough void space for expansion. Novel structures could provide various functionalities including promoting electronic contact with conductive additives, enlarging the surface area of active material, and shortening ionic diffusion pathway. Moreover, some synthesis routes mentioned additional conductive carbon coating, doping with functional element, and composite material formation, which can largely enhance the electrochemical performance of the prepared anode material as well.

Nevertheless, structured silicon based anode material is still hindered for the practical application, considering the high-cost and complicated synthesis procedures, such as expensive precursors $\left(\mathrm{SiH}_{4}\right)$ and catalysts (Au colloids), highcost techniques (CVD), and nonscalable steps (HF-etching). For the purpose of commercializing silicon anode material with high performance, great efforts are still demanded for developing low-cost and scalable synthesis methodologies.

\section{Conflicts of Interest}

The authors declare that there are no conflicts of interest regarding the publication of this paper.

\section{Acknowledgments}

This work is partially supported by the National Science Foundation (NSF) through NSF-CBET 1505943 and 1336057, ACS Petroleum Research Fund (PRF no. 53560-DNI 10), and DOE STTR (DE-SC0013831). The authors are also grateful for financial support from the University of Akron.

\section{References}

[1] J.-M. Tarascon and M. Armand, "Issues and challenges facing rechargeable lithium batteries," Nature, vol. 414, pp. 359-367, 2001.

[2] C. K. Chan, H. L. Peng, G. Liu et al., "High-performance lithium battery anodes using silicon nanowires," Nature Nanotechnology, vol. 3, pp. 31-35, 2008.

[3] M. Armand and J.-M. Tarascon, "Building better batteries," Nature, vol. 451, pp. 652-657, 2008.

[4] J. B. Goodenough and Y. Kim, "Challenges for rechargeable Li batteries," Chemistry of Materials, vol. 22, no. 3, pp. 587-603, 2010.

[5] Y. Yang, J.-G. Ren, X. Wang et al., "Graphene encapsulated and $\mathrm{SiC}$ reinforced silicon nanowires as an anode material for lithium ion batteries," Nanoscale, vol. 5, no. 18, pp. 8689-8694, 2013.

[6] E. Peled, C. Menachem, D. Bar-Tow, and A. Melman, "Improved graphite anode for lithium-ion batteries chemically-bonded solid electrolyte interface and nanochannel formation," Journal of The Electrochemical Society, vol. 143, no. 1, pp. L4-L7, 1996.

[7] P. G. Bruce, S. A. Freunberger, L. J. Hardwick, and J.-M. Tarascon, "Erratum: $\mathrm{Li}-\mathrm{O}_{2}$ and $\mathrm{L}-\mathrm{S}$ batteries with high energy storage," Nature Materials, vol. 11, p. 172, 2012.

[8] G. Hwang, J.-M. Kim, D. Hong et al., "Multifunctional natural agarose as an alternative material for high-performance rechargeable lithium-ion batteries," Green Chemistry, vol. 18, no. 9, pp. 2710-2716, 2016.

[9] G. Wang, Z. Wen, L. Du, S. Li, S. Ji, and J. Sun, "A core-shell $\mathrm{Si} @ \mathrm{Nb}_{2} \mathrm{O}_{5}$ composite as an anode material for lithium-ion batteries," RSC Advances, vol. 6, no. 46, pp. 39728-39733, 2016.

[10] A. N. Dey, "Electrochemical alloying of lithium in organic electrolytes," Journal of the Electrochemical Society, vol. 118, no. 10, pp. 1547-1549, 1971.

[11] B. A. Boukamp, T. Journal, M. C. Weeks et al., "All-solid lithium electrodes with mixed-conductor matrix," Journal of the Electrochemical Society, vol. 128, p. 725, 1981.

[12] L. Ji, K.-H. Jung, A. J. Medford, and X. Zhang, "Electrospun polyacrylonitrile fibers with dispersed Si nanoparticles and their electrochemical behaviors after carbonization," Journal of Materials Chemistry, vol. 19, no. 28, pp. 4992-4997, 2009.

[13] B. Hertzberg, A. Alexeev, and G. Yushin, "Deformations in Si-Li anodes upon electrochemical alloying in nano-confined space," Journal of the American Chemical Society, vol. 132, no. 25, pp. 8548-8549, 2010.

[14] R. A. Sharma and R. N. Seefurth, "Thermodynamic Properties of the Lithium-Silicon System," Journal of the Electrochemical Society, vol. 123, no. 12, pp. 1763-1768, 1976.

[15] W. J. Weydanz, M. Wohlfahrt-Mehrens, and R. A. Huggins, "A room temperature study of the binary lithium-silicon and the ternary lithium-chromium-silicon system for use in rechargeable lithium batteries," Journal of Power Sources, vol. 81-82, pp. 237-242, 1999.

[16] J. W. Kim, J. H. Ryu, K. T. Lee, and S. M. Oh, "Improvement of silicon powder negative electrodes by copper electroless deposition for lithium secondary batteries," Journal of Power Sources, vol. 147, no. 1-2, pp. 227-233, 2005.

[17] L. Y. Beaulieu, K. W. Eberman, R. L. Turner, L. J. Krause, and J. R. Dahn, "Colossal reversible volume changes in lithium alloys," Electrochemical and Solid-State Letters, vol. 4, no. 9, pp. A137A140, 2001. 
[18] Q. Zhang, X. Xiao, W. Zhou, Y.-T. Cheng, and M. W. Verbrugge, "Toward high cycle efficiency of silicon-based negative electrodes by designing the solid electrolyte interphase," Advanced Energy Materials, vol. 5, no. 5, Article ID 1401398, 2015.

[19] P. Verma, P. Maire, and P. Novák, "A review of the features and analyses of the solid electrolyte interphase in Li-ion batteries," Electrochimica Acta, vol. 55, no. 22, pp. 6332-6341, 2010.

[20] D. Aurbach, "Review of selected electrode-solution interactions which determine the performance of $\mathrm{Li}$ and $\mathrm{Li}$ ion batteries," Journal of Power Sources, vol. 89, no. 2, pp. 206-218, 2000.

[21] C. K. Chan, R. Ruffo, S. S. Hong, and Y. Cui, "Surface chemistry and morphology of the solid electrolyte interphase on silicon nanowire lithium-ion battery anodes," Journal of Power Sources, vol. 189, no. 2, pp. 1132-1140, 2009.

[22] J. H. Ryu, J. W. Kim, Y.-E. Sung, and S. M. Oh, "Failure modes of silicon powder negative electrode in lithium secondary batteries," Electrochemical and Solid-State Letters, vol. 7, no. 10, pp. A306-A309, 2004.

[23] M.-H. Park, M. G. Kim, J. Joo et al., "Silicon nanotube battery anodes," Nano Letters, vol. 9, no. 11, pp. 3844-3847, 2009.

[24] S.-H. Ng, J. Wang, D. Wexler, K. Konstantinov, Z.-P. Guo, and H. Liu, "Highly reversible lithium storage in spheroidal carbon-coated silicon nanocomposites as anodes for lithiumion batteries," Angewandte Chemie, vol. 45, no. 41, pp. 68966899, 2006.

[25] P. G. Bruce, B. Scrosati, and J.-M. Tarascon, "Nanomaterials for rechargeable lithium batteries," Angewandte Chemie, vol. 47, no. 16, pp. 2930-2946, 2008.

[26] Y. Wu, Y. Cui, L. Huynh, C. J. Barrelet, D. C. Bell, and C. M. Lieber, "Controlled growth and structures of molecular-scale silicon nanowires," Nano Letters, vol. 4, no. 3, pp. 433-436, 2004.

[27] T. Song, J. L. Xia, J.-H. Lee et al., "Arrays of sealed silicon nanotubes as anodes for lithium ion batteries," Nano Letters, vol. 10, no. 5, pp. 1710-1716, 2010.

[28] R. Mukherjee, R. Krishnan, T.-M. Lu, and N. Koratkar, "Nanostructured electrodes for high-power lithium ion batteries," Nano Energy, vol. 1, no. 4, pp. 518-533, 2012.

[29] A. Magasinski, B. Zdyrko, I. Kovalenko et al., "Toward efficient binders for Li-ion battery Si-based anodes: polyacrylic acid," ACS Applied Materials \& Interfaces, vol. 2, no. 11, pp. 3004-3010, 2010.

[30] X. Chen, C. Li, M. Gratzel, R. Kostecki, and S. S. Mao, "Nanomaterials for renewable energy production and storage," Chemical Society Reviews, vol. 41, no. 23, pp. 7909-7937, 2012.

[31] X. H. Liu, L. Zhong, S. Huang, S. X. Mao, T. Zhu, and J. Y. Huang, "Size-dependent fracture of silicon nanoparticles during lithiation," ACS Nano, vol. 6, no. 2, pp. 1522-1531, 2012.

[32] H. Li, X. Huang, L. Chen et al., “The crystal structural evolution of nano-Si anode caused by lithium insertion and extraction at room temperature," Solid State Ionics, vol. 135, no. 1-4, pp. 181191, 2000.

[33] B. Key, R. Bhattacharyya, M. Morcrette, V. Seznéc, J.-M. Tarascon, and C. P. Grey, "Real-time NMR investigations of structural changes in silicon electrodes for lithium-ion batteries," Journal of the American Chemical Society, vol. 131, no. 26, pp. 9239-9249, 2009.

[34] C. K. Chan, R. Ruffo, S. S. Hong, R. A. Huggins, and Y. Cui, "Structural and electrochemical study of the reaction of lithium with silicon nanowires," Journal of Power Sources, vol. 189, no. 1, pp. 34-39, 2009.
[35] X. H. Liu, H. Zheng, L. Zhong et al., "Anisotropic swelling and fracture of silicon nanowires during lithiation," Nano Letters, vol. 11, no. 8, pp. 3312-3318, 2011.

[36] S. W. Lee, M. T. McDowell, J. W. Choi, and Y. Cui, "Anomalous shape changes of silicon nanopillars by electrochemical lithiation," Nano Letters, vol. 11, no. 7, pp. 3034-3039, 2011.

[37] J. L. Goldman, B. R. Long, A. A. Gewirth, and R. G. Nuzzo, "Strain anisotropies and self-limiting capacities in singlecrystalline 3D silicon microstructures: models for high energy density lithium-ion battery anodes," Advanced Functional Materials, vol. 21, no. 13, pp. 2412-2422, 2011.

[38] S. W. Lee, M. T. McDowell, L. A. Berla, W. D. Nix, and Y. Cui, "Fracture of crystalline silicon nanopillars during electrochemical lithium insertion," Proceedings of the National Academy of Sciences of the United States of America, vol. 109, no. 11, pp. 40804085, 2012.

[39] A. S. Aricò, P. Bruce, B. Scrosati, J.-M. Tarascon, and W. van Schalkwijk, "Nanostructured materials for advanced energy conversion and storage devices," Nature Materials, vol. 4, pp. 366-377, 2005.

[40] L. Liu, J. Lyu, T. Li, and T. Zhao, "Well-constructed silicon-based materials as high-performance lithium-ion battery anodes," Nanoscale, vol. 8, no. 2, pp. 701-722, 2016.

[41] A. G. Kannan, S. H. Kim, H. S. Yang, and D. Kim, "Silicon nanoparticles grown on a reduced graphene oxide surface as high-performance anode materials for lithium-ion batteries," RSC Advances, vol. 6, no. 30, pp. 25159-25166, 2016.

[42] A. Magasinski, P. Dixon, B. Hertzberg, A. Kvit, J. Ayala, and G. Yushin, "High-performance lithium-ion anodes using a hierarchical bottom-up approach," Nature Materials, vol. 9, no. 4, pp. 353-358, 2010.

[43] C. Pang, H. Song, N. Li, and C. Wang, "A strategy for suitable mass production of a hollow Si@C nanostructured anode for lithium ion batteries," RSC Advances, vol. 5, no. 9, pp. 67826789, 2015.

[44] H. Ma, F. Cheng, J. Chen et al., "Nest-like silicon nanospheres for high-capacity lithium storage," Advanced Materials, vol. 19, no. 22, pp. 4067-4070, 2007.

[45] Y. Yao, M. T. McDowell, I. Ryu et al., "Interconnected silicon hollow nanospheres for lithium-ion battery anodes with long cycle life," Nano Letters, vol. 11, no. 7, pp. 2949-2954, 2011.

[46] H. Wu, L. Hu, M. W. Rowell et al., "Electrospun metal nanofiber webs as high-performance transparent electrode," Nano Letters, vol. 10, no. 10, pp. 4242-4248, 2010.

[47] N. Liu, H. Wu, M. T. McDowell, Y. Yao, C. Wang, and Y. Cui, "A yolk-shell design for stabilized and scalable Li-ion battery alloy anodes," Nano Letters, vol. 12, no. 6, pp. 3315-3321, 2012.

[48] Z. Lu, N. Liu, H.-W. Lee et al., "Nonfilling carbon coating of porous silicon micrometer-sized particles for highperformance lithium battery anodes," ACS Nano, vol. 9, no. 3, pp. 2540-2547, 2015.

[49] T. Song, H. Cheng, H. Choi et al., "Si/Ge double-layered nanotube array as a lithium ion battery anode," ACS Nano, vol. 6, no. 1, pp. 303-309, 2012.

[50] A. I. Hochbaum, R. Fan, R. He, and P. Yang, "Controlled growth of Si nanowire arrays for device integration," Nano Letters, vol. 5, no. 3, pp. 457-460, 2005.

[51] A. T. Heitsch, D. D. Fanfair, H.-Y. Tuan, and B. A. Korgel, "Solution-liquid-solid (SLS) growth of silicon nanowires," Journal of the American Chemical Society, vol. 130, no. 16, pp. 54365437, 2008. 
[52] W. K. Choi, T. H. Liew, M. K. Dawood, H. I. Smith, C. V. Thompson, and M. H. Hong, "Synthesis of silicon nanowires and nanofin arrays using interference lithography and catalytic etching," Nano Letters, vol. 8, no. 11, pp. 3799-3802, 2008.

[53] P. R. Abel, A. M. Chockla, Y.-M. Lin et al., "Nanostructured $\mathrm{Si}_{(1-x)} \mathrm{Ge}_{x}$ for tunable thin film lithium-ion battery anodes," ACS Nano, vol. 7, no. 3, pp. 2249-2257, 2013.

[54] P. R. Abel, Y.-M. Lin, H. Celio, A. Heller, and C. B. Mullins, "Improving the stability of nanostructured silicon thin film lithium-ion battery anodes through their controlled oxidation," ACS Nano, vol. 6, no. 3, pp. 2506-2516, 2012.

[55] M. Ge, X. Fang, J. Rong, and C. Zhou, "Review of porous silicon preparation and its application for lithium-ion battery anodes," Nanotechnology, vol. 24, no. 42, Article ID 422001, 2013.

[56] M.-J. Chun, H. Park, S. Park, and N.-S. Choi, "Bicontinuous structured silicon anode exhibiting stable cycling performance at elevated temperature," RSC Advances, vol. 3, no. 44, pp. 21320-21325, 2013.

[57] Z. Chen, Y. Qin, K. Amine, and Y.-K. Sun, "Role of surface coating on cathode materials for lithium-ion batteries," Journal of Materials Chemistry, vol. 20, no. 36, pp. 7606-7612, 2010.

[58] J. Wang, J. Yang, Y. Tang et al., "Size-dependent surface phase change of lithium iron phosphate during carbon coating," Nature Communications, vol. 5, article 3415, 2014.

[59] Z. W. Seh, W. Li, J. J. Cha et al., "Sulphur-TiO 2 yolk-shell nanoarchitecture with internal void space for long-cycle lithiumsulphur batteries," Nature Communications, vol. 4, article 1331, 2013.

[60] N. Liu, Z. Lu, J. Zhao et al., "A pomegranate-inspired nanoscale design for large-volume-change lithium battery anodes," Nature Nanotechnology, vol. 9, pp. 187-192, 2014.

[61] K. Zhao, M. Pharr, L. Hartle, J. J. Vlassak, and Z. Suo, "Fracture and debonding in lithium-ion batteries with electrodes of hollow core-shell nanostructures," Journal of Power Sources, vol. 218, pp. 6-14, 2012.

[62] Y. Hu, X. Zhao, and Z. Suo, "Averting cracks caused by insertion reaction in lithium-ion batteries," Journal of Materials Research, vol. 25, no. 6, pp. 1007-1010, 2010.

[63] R. A. Huggins and W. D. Nix, "Decrepitation model for capacity loss during cycling of alloys in rechargeable electrochemical systems," Ionics, vol. 6, no. 1-2, pp. 57-63, 2000.

[64] C. Q. Sun, "Size dependence of nanostructures: impact of bond order deficiency," Progress in Solid State Chemistry, vol. 35, no. 1, pp. 1-159, 2007.

[65] C. Q. Sun, "Surface and nanosolid core-level shift: impact of atomic coordination-number imperfection," Physical Review B, vol. 69, no. 4-15, Article ID 045105, 2004.

[66] Z. Ma, T. Li, Y. L. Huang, J. Liu, Y. Zhou, and D. Xue, "Critical silicon-anode size for averting lithiation-induced mechanical failure of lithium-ion batteries," RSC Advances, vol. 3, no. 20, pp. 7398-7402, 2013.

[67] H. Kim, M. Seo, M.-H. Park, and J. Cho, "A critical size of silicon nano-anodes for lithium rechargeable batteries," Angewandte Chemie, vol. 49, no. 12, pp. 2146-2149, 2010.

[68] J. Ryu, D. Hong, M. Shin, and S. Park, "Multiscale hyperporous silicon flake anodes for high initial coulombic efficiency and cycle stability," ACS Nano, vol. 10, no. 11, pp. 10589-10597, 2016.

[69] W. Chen, Z. Fan, A. Dhanabalan, C. Chen, and C. Wang, "Mesoporous silicon anodes prepared by magnesiothermic reduction for lithium ion batteries," Journal of the Electrochemical Society, vol. 158, no. 9, pp. A1055-A1059, 2011.
[70] Y. Shi, F. Zhang, Y.-S. Hu et al., "Low-temperature pseudomorphic transformation of ordered hierarchical macro-mesoporous $\mathrm{SiO}_{2} / \mathrm{C}$ nanocomposite to $\mathrm{SiC}$ via magnesiothermic reduction," Journal of the American Chemical Society, vol. 132, no. 16, pp. 5552-5553, 2010.

[71] X. Zuo, Y. Xia, Q. Ji et al., "Self-templating construction of 3D hierarchical macro-/mesoporous silicon from 0D silica nanoparticles," ACS Nano, vol. 11, no. 1, pp. 889-899, 2017.

[72] J. Xie, G. Wang, Y. Huo, S. Zhang, G. Cao, and X. Zhao, "Nanostructured silicon spheres prepared by a controllable magnesiothermic reduction as anode for lithium ion batteries," Electrochimica Acta, vol. 135, pp. 94-100, 2014.

[73] Z. Bao, M. R. Weatherspoon, S. Shian et al., "Chemical reduction of three-dimensional silica micro-assemblies into microporous silicon replicas," Nature, vol. 446, no. 7132, pp. 172175, 2007.

[74] L. Shen, X. Guo, X. Fang, Z. Wang, and L. Chen, "Magnesiothermically reduced diatomaceous earth as a porous silicon anode material for lithium ion batteries," Journal of Power Sources, vol. 213, pp. 229-232, 2012.

[75] C. Wang, H. Wu, Z. Chen, M. T. McDowell, Y. Cui, and Z. Bao, "Self-healing chemistry enables the stable operation of silicon microparticle anodes for high-energy lithium-ion batteries," Nature Chemistry, vol. 5, pp. 1042-1048, 2013.

[76] R. Yi, F. Dai, M. L. Gordin, H. Sohn, and D. Wang, "Influence of silicon nanoscale building blocks size and carbon coating on the performance of micro-sized si-c composite li-ion anodes," Advanced Energy Materials, vol. 3, no. 11, pp. 1507-1515, 2013.

[77] Y.-W. Chen, Y.-H. Tang, L.-Z. Pei, and C. Guo, "Self-assembled silicon nanotubes grown from silicon monoxide," Advanced Materials, vol. 17, no. 5, pp. 564-567, 2005.

[78] J.-K. Yoo, J. Kim, Y. S. Jung, and K. Kang, "Scalable fabrication of silicon nanotubes and their application to energy storage," Advanced Materials, vol. 24, no. 40, pp. 5452-5456, 2012.

[79] K. Li, W. Wang, and D. Cao, "Novel chemical sensor for CO and NO: silicon nanotube," The Journal of Physical Chemistry C, vol. 115, no. 24, pp. 12015-12022, 2011.

[80] H. M. Fahad, C. E. Smith, J. P. Rojas, and M. M. Hussain, "Silicon nanotube field effect transistor with core-shell gate stacks for enhanced high-performance operation and area scaling benefits," Nano Letters, vol. 11, no. 10, pp. 4393-4399, 2011.

[81] J. Sha, J. Niu, X. Ma et al., "Silicon Nanotubes," Advanced Materials, vol. 14, no. 17, pp. 1219-1221, 2002.

[82] Z. Wen, G. Lu, S. Mao et al., "Silicon nanotube anode for lithium-ion batteries," Electrochemistry Communications, vol. 29, pp. 67-70, 2013.

[83] H. Wu, G. Chan, J. W. Choi et al., "Stable cycling of double-walled silicon nanotube battery anodes through solid-electrolyte interphase control," Nature Nanotechnology, vol. 7, pp. 310-315, 2012.

[84] P. Castrucci, M. Scarselli, M. De Crescenzi et al., "Silicon nanotubes: synthesis and characterization," Thin Solid Films, vol. 508, no. 1-2, pp. 226-230, 2006.

[85] R. G. Treuting and S. M. Arnold, "Orientation habits of metal whiskers," Acta Metallurgica, vol. 5, no. 10, p. 598, 1957.

[86] S. Zhou, X. Liu, and D. Wang, "Si/TiSi ${ }_{2}$ heteronanostructures as highcapacity anode material For Li ion batteries," Nano Letters, vol. 10, no. 3, pp. 860-863, 2010.

[87] D. Tan, B. Liu, D. Chen, and G. Shen, "Si@SiO nanowires/carbon textiles cable-type anodes for high-capacity 
reversible lithium-ion batteries," RSC Advances, vol. 4, no. 35, pp. 18391-18396, 2014.

[88] I. Lombardi, A. I. Hochbaum, P. Yang, C. Carraro, and R. Maboudian, "Synthesis of high density, size-controlled Si nanowire arrays via porous anodic alumina mask," Chemistry of Materials, vol. 18, no. 4, pp. 988-991, 2006.

[89] G. L. Che, B. B. Lakshmi, E. R. Fisher, and C. R. Martin, "Carbon nanotubule membranes for electrochemical energy storage and production," Nature, vol. 393, no. 6683, pp. 346-349, 1998.

[90] K. T. Nam, D.-W. Kim, P. J. Yoo et al., "Virus-enabled synthesis and assembly of nanowires for lithium ion battery electrodes," Science, vol. 312, no. 5775, pp. 885-888, 2008.

[91] K. M. Shaju, F. Jiao, A. D?bart, P. G. Bruce, and A. Dbart, "Mesoporous and nanowire $\mathrm{Co}_{3} \mathrm{O}_{4}$ as negative electrodes for rechargeable lithium batteries," Physical Chemistry Chemical Physics, vol. 9, no. 15, pp. 1837-1842, 2007.

[92] N. Li, C. J. Patrissi, G. Che, and C. R. Martin, "Rate capabilities of nanostructured LiMn2O4 electrodes in aqueous electrolyte," Journal of the Electrochemical Society, vol. 147, no. 6, pp. 20442049, 2000 .

[93] H. Chen, Z. Dong, Y. Fu, and Y. Yang, "Silicon nanowires with and without carbon coating as anode materials for lithium-ion batteries," Journal of Solid State Electrochemistry, vol. 14, no. 10, pp. 1829-1834, 2010.

[94] H. T. Nguyen, F. Yao, M. R. Zamfir et al., "Highly interconnected Si nanowires for improved stability Li-ion battery anodes," Advanced Energy Materials, vol. 1, no. 6, pp. 1154-1161, 2011.

[95] N. Jayaprakash, N. Kalaiselvi, and C. H. Doh, "A new class of tailor-made $\mathrm{Fe}_{0.92} \mathrm{Mn}_{0.08} \mathrm{Si}_{2}$ lithium battery anodes: effect of composite and carbon coated $\mathrm{Fe}_{0.92} \mathrm{Mn}_{0.08} \mathrm{Si}_{2}$ anodes," Intermetallics, vol. 15, no. 3, pp. 442-450, 2007.

[96] J. D. Holmes, "Control of thickness and orientation of solutiongrown silicon nanowires," Science, vol. 287, no. 5457, pp. 14711473, 2000.

[97] A. M. Chockla, J. T. Harris, V. A. Akhavan et al., "Silicon nanowire fabric as a lithium ion battery electrode material," Journal of the American Chemical Society, vol. 133, no. 51, pp. 20914-20921, 2011.

[98] C. K. Chan, R. N. Patel, M. J. O’Connell, B. A. Korgel, and Y. Cui, "Solution-grown silicon nanowires for lithium-ion battery anodes," ACS Nano, vol. 4, no. 3, pp. 1443-1450, 2010.

[99] T. Hanrath and B. A. Korgel, "Supercritical fluid-liquid-solid (SFLS) synthesis of $\mathrm{Si}$ and Ge nanowires seeded by colloidal metal nanocrystals," Advanced Materials, vol. 15, no. 5, pp. 437440, 2003.

[100] H. I. Liu, "Self-limiting oxidation of Si nanowires," Journal of Vacuum Science \& Technology B, Nanotechnology and Microelectronics: Materials, Processing, Measurement, and Phenomena, vol. 11, no. 6, article 2532, 1993.

[101] C. M. Hsu, S. T. Connor, M. X. Tang, and Y. Cui, "Waferscale silicon nanopillars and nanocones by Langmuir-Blodgett assembly and etching," Applied Physics Letters, vol. 93, Article ID 133109, 2008.

[102] K. J. Morton, G. Nieberg, S. Bai, and S. Y. Chou, "Waferscale patterning of sub- $40 \mathrm{~nm}$ diameter and high aspect ratio $(>50: 1)$ silicon pillar arrays by nanoimprint and etching," Nanotechnology, vol. 19, no. 34, Article ID 345301, 2008.

[103] J. R. Heath, "Superlattice nanowire pattern transfer (SNAP)," Accounts of Chemical Research, vol. 41, no. 12, pp. 1609-1617, 2008.
[104] K. Peng, J. Jie, W. Zhang, and S.-T. Lee, "Silicon nanowires for rechargeable lithium-ion battery anodes," Applied Physics Letters, vol. 93, no. 3, Article ID 033105, 2008.

[105] R. Huang, X. Fan, W. Shen, and J. Zhu, "Carbon-coated silicon nanowire array films for high-performance lithium-ion battery anodes," Applied Physics Letters, vol. 95, Article ID 133119, 2009.

[106] M. Ge, J. Rong, X. Fang, and C. Zhou, "Porous doped silicon nanowires for lithium ion battery anode with long cycle life," Nano Letters, vol. 12, no. 5, pp. 2318-2323, 2012.

[107] V. L. Chevrier and J. R. Dahn, "First principles model of amorphous silicon lithiation," Journal of the Electrochemical Society, vol. 156, no. 6, pp. A454-A458, 2009.

[108] M. T. McDowell, S. W. Lee, I. Ryu et al., "Novel size and surface oxide effects in silicon nanowires as lithium battery anodes," Nano Letters, vol. 11, no. 9, pp. 4018-4025, 2011.

[109] E. Markevich, G. Salitra, A. Rosenman, Y. Talyosef, D. Aurbach, and A. Garsuch, "High performance of thick amorphous columnar monolithic film silicon anodes in ionic liquid electrolytes at elevated temperature," RSC Advances, vol. 4, no. 89, pp. 48572-48575, 2014.

[110] J. P. Maranchi, A. F. Hepp, A. G. Evans, N. T. Nuhfer, and P. N. Kumta, "Interfacial properties of the a-SiCu: Active-inactive thin-film anode system for lithium-ion batteries," Journal of the Electrochemical Society, vol. 153, no. 6, pp. A1246-A1253, 2006.

[111] X. Xiao, P. Liu, M. W. Verbrugge, H. Haftbaradaran, and H. Gao, "Improved cycling stability of silicon thin film electrodes through patterning for high energy density lithium batteries," Journal of Power Sources, vol. 196, no. 3, pp. 1409-1416, 2011.

[112] S. K. Soni, B. W. Sheldon, X. Xiao et al., "Stress mitigation during the lithiation of patterned amorphous Si islands," Journal of the Electrochemical Society, vol. 159, no. 1, pp. A38-A43, 2012.

[113] J. P. Maranchi, A. F. Hepp, and P. N. Kumta, "High capacity, reversible silicon thin-film anodes for lithium-ion batteries," Electrochemical and Solid-State Letters, vol. 6, no. 9, pp. A198A201, 2003.

[114] J. Graetz, C. C. Ahn, R. Yazami, and B. Fultz, "Highly reversible lithium storage in nanostructured silicon," Electrochemical and Solid-State Letters, vol. 6, no. 9, pp. A194-A197, 2003.

[115] S.-W. Song, K. A. Striebel, R. P. Reade, G. A. Roberts, and E. J. Cairns, "Electrochemical studies of nanocrystalline $\mathrm{Mg}_{2} \mathrm{Si}$ thin film electrodes prepared by pulsed laser deposition," Journal of the Electrochemical Society, vol. 150, no. 1, pp. A121-A127, 2003.

[116] S. Bourderau, T. Brousse, and D. M. Schleich, "Amorphous silicon as a possible anode material for Li-ion batteries," Journal of Power Sources, vol. 81-82, pp. 233-236, 1999.

[117] H. Jung, M. Park, S. H. Han, H. Lim, and S.-K. Joo, "Amorphous silicon thin-film negative electrode prepared by low pressure chemical vapor deposition for lithium-ion batteries," Solid State Communications, vol. 125, no. 7-8, pp. 387-390, 2003.

[118] L. B. Chen, J. Y. Xie, H. C. Yu, and T. H. Wang, "An amorphous Si thin film anode with high capacity and long cycling life for lithium ion batteries," Journal of Applied Electrochemistry, vol. 39, no. 8, pp. 1157-1162, 2009.

[119] H. Haftbaradaran and H. Gao, "Ratcheting of silicon island electrodes on substrate due to cyclic intercalation," Applied Physics Letters, vol. 100, no. 12, Article ID 121907, 2012.

[120] M. N. Obrovac and L. Christensen, "Structural changes in silicon anodes during lithium insertion/extraction," Electrochemical and Solid-State Letters, vol. 7, no. 5, pp. A93-A96, 2004.

[121] T. D. Hatchard and J. R. Dahn, "In situ XRD and electrochemical study of the reaction of lithium with amorphous silicon," Journal 
of the Electrochemical Society, vol. 151, no. 6, pp. A838-A842, 2004.

[122] H.-C. Shin, J. A. Corno, J. L. Gole, and M. Liu, "Porous silicon negative electrodes for rechargeable lithium batteries," Journal of Power Sources, vol. 139, no. 1-2, pp. 314-320, 2005.

[123] M. Green, E. Fielder, B. Scrosati, M. Wachtler, and J. Serra Moreno, "Structured silicon anodes for lithium battery applications," Electrochemical and Solid-State Letters, vol. 6, no. 5, pp. A75-A79, 2003. 

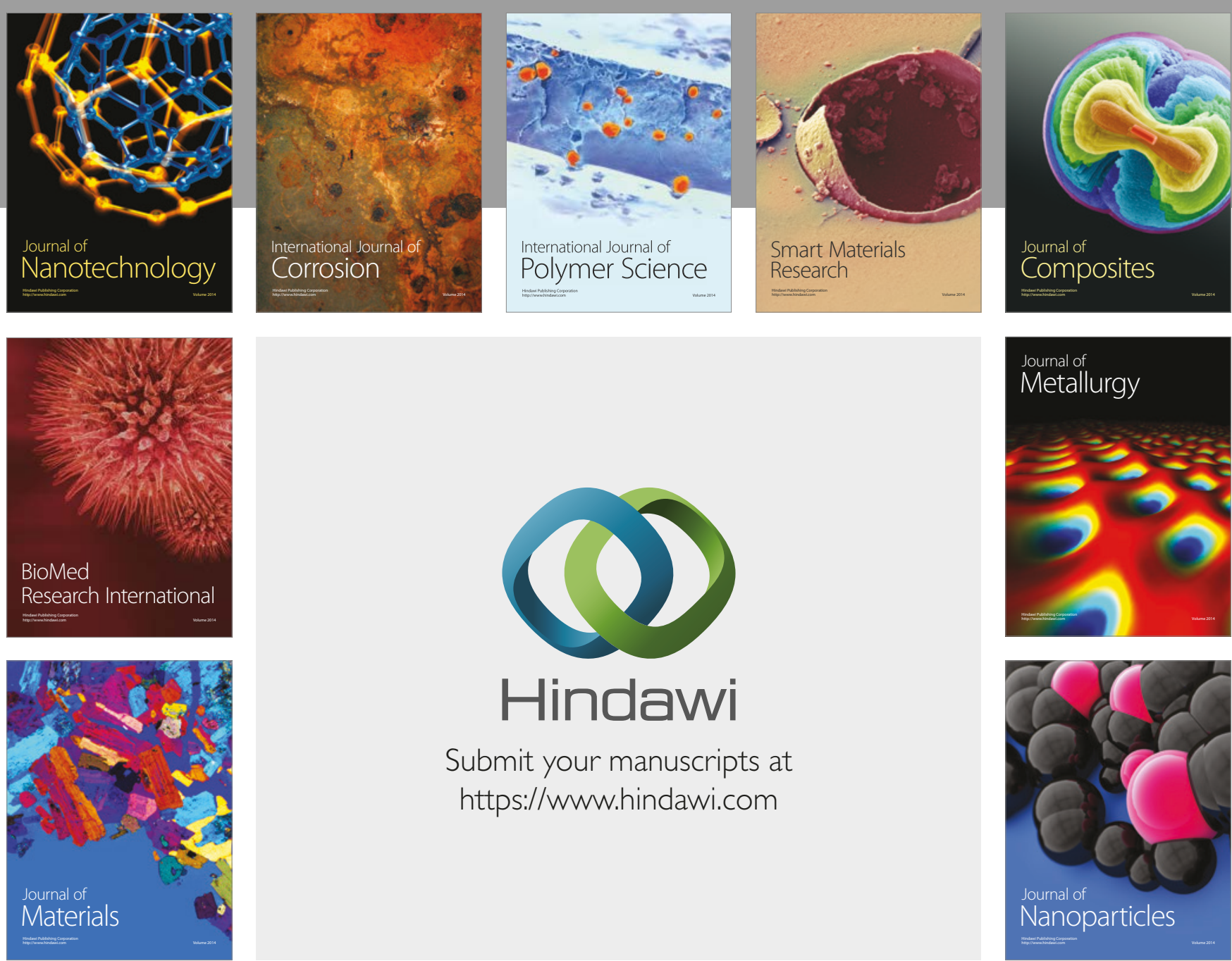

\section{Hindawi}

Submit your manuscripts at

https://www.hindawi.com
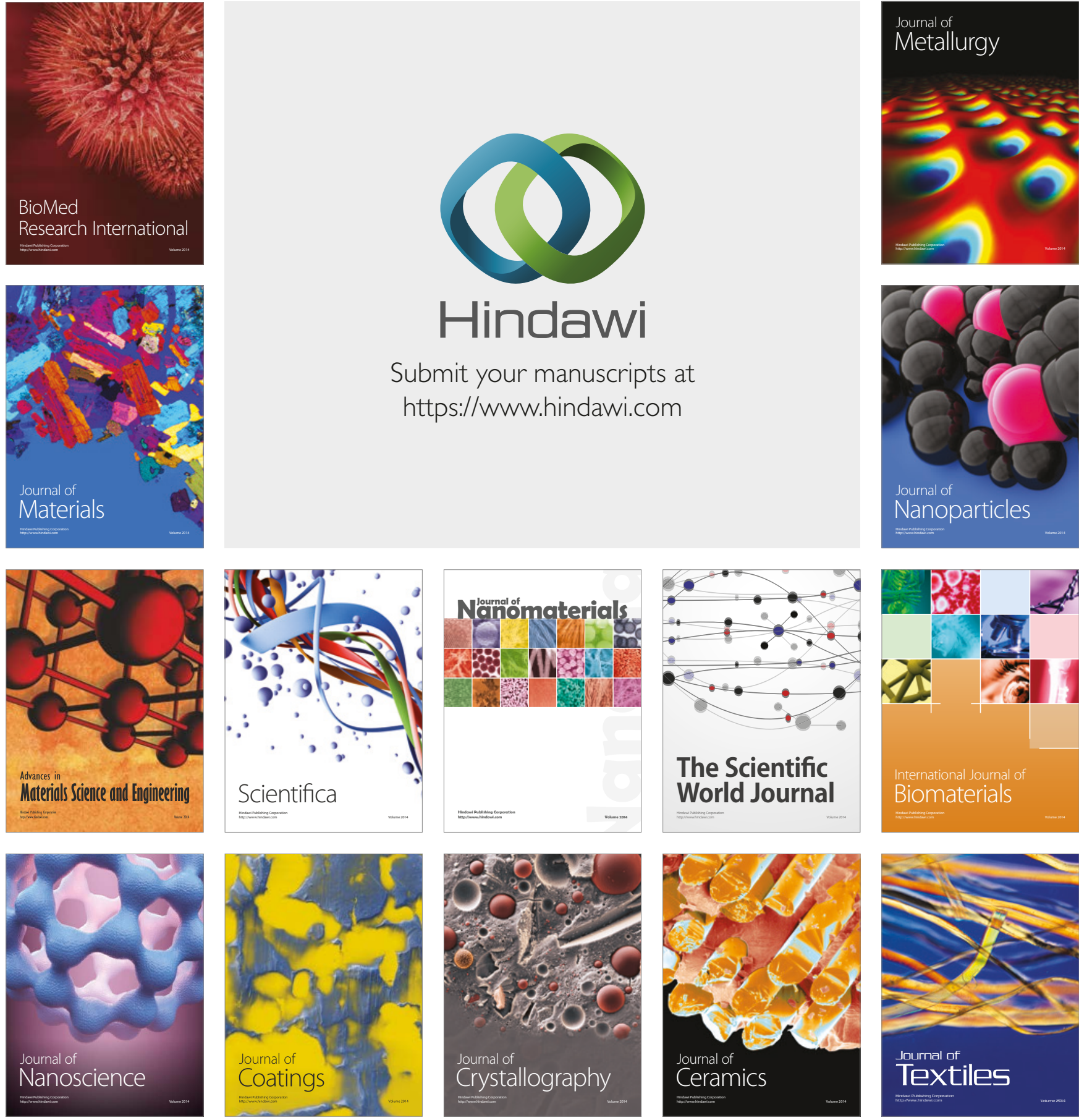

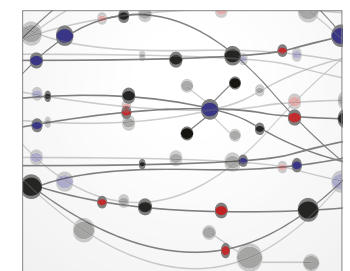

The Scientific World Journal
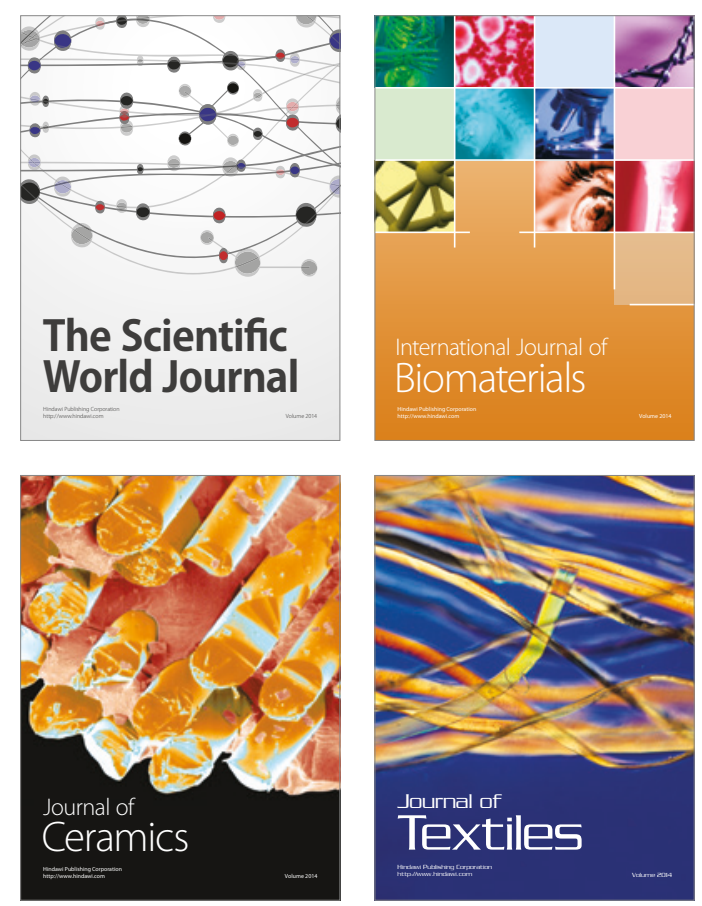